\title{
Immunohistochemical localization of active caspase- 3 in the mouse ovary: growth and atresia of small follicles
}

\author{
M. A. Fenwick and P. R. Hurst ${ }^{*}$ \\ Department of Anatomy and Structural Biology, University of Otago, School of Medical \\ Sciences, PO Box 913, Dunedin, New Zealand
}

Caspase-3 belongs to a family of highly conserved cysteine proteases that mediate the course of apoptotic cell suicide. It is recognized that ovarian follicular atresia is associated with apoptosis, a process that has been characterized mainly in larger antral follicles. The aims of this study were to investigate the expression of caspase- 3 in the mouse ovary, and determine whether active caspase- 3 is present within smaller follicles, which may constitute the resting pool. The inactive enzyme was expressed as a $32 \mathrm{kDa}$ band on a western blot of tissue extracts, whereas the active form was localized immunohistochemically. Bromodeoxyuridine (BrdU) was administered to mice $(n=7)$ during a $12 \mathrm{~h}$ period and subsequently localized to identify potentially quiescent follicles. Measurements of BrdU-positive cells in the mouse ovary were extrapolated with data obtained by morphometric analyses of small follicles using the nucleator technique. BrdU was incorporated into the granulosa cells of follicles regardless of size and the number of cells they contained, but was absent in a large proportion $(89 \%)$ of small, single layered follicles. Active caspase- 3 was localized to both the oocyte and granulosa cells of follicles that were considered to be undergoing atresia, but was not localized to the granulosa cells of any small, single layered follicles. The results of this study indicate that, in small follicles, granulosa cell proliferation occurs independently of the size of follicles and the number of constituent cells, and that follicles of this type may be inherently less susceptible to the normal physiological factors that induce atresia.

\section{Introduction}

The mammalian ovary contains follicles that are destined to undergo atresia unless rescued by endocrine or local paracrine survival factors (Kaipia and Hsueh, 1997). Atresia occurs as a consequence of apoptosis (programmed cell death) of constituent oocyte or follicle cells, or both, and is a highly structured sequence of biochemical events initiated in response to a variety of stimuli in the ovary, including growth factor deprivation (Kaipia and Hsueh, 1997), $\gamma$ irradiation (Lee et al., 2000), accumulation of metabolites (Tilly, 1996) and induction via receptor mediated signals, such as the Fas ligand (Sakamaki et al., 1997). Furthermore, the specific apoptotic events that take place in response to these stimuli are now becoming more distinct, including the Bcl-2 (and related protein) pathway (Tilly et al., 1995) and those that are independent of mitochondrial disruption, such as the Fas receptor pathway (Hakuno et al., 1996). The earliest known molecular convergence point for most of these cascades is the effector enzyme, caspase-3 (Cohen, 1997). This enzyme, when activated, exerts its effect downstream by cleaving essential nuclear proteins, including DNA fragmentation factor, poly (ADP-ribose) polymerase (PARP) and the structural nuclear lamins (Earnshaw et al.,

*Correspondence

Email: peter.hurst@stonebow.otago.ac.nz
1999). The expression and activation of caspase- 3 induce apoptosis in a number of different types of cell (Earnshaw et al., 1999) and its expression has been found in the ovary of hens (Johnson and Bridgham, 2000), quails (Van Nassauw et al., 1999), rats (Boone and Tsang, 1998) and mice and humans (Matikainen et al., 2001). The localization of the active form of caspase- 3 not only implicates it in follicular atresia but also serves as a useful and reliable marker for the identification of apoptotic cells.

The process of atresia can be recognized in follicles that have reached the multilayered-small preantral stage of development, a period when constituent granulosa cells express gonadotrophin receptors (Findlay and Drummond, 1999). Several reports indicate, however, that follicular atresia occurs at all stages of development, including smaller follicles classified as resting (Baker, 1963; Gougeon, 1996; Morita and Tilly, 1999; Perez et al., 1999), which are not under the direct developmental control of gonadotrophins. As apoptosis is so prevalent in the ovary, some protective mechanisms may predominate in follicles that remain dormant throughout the course of the reproductive lifespan, thus making them more resistant to atresia.

Recruitment of healthy, resting follicles, however, involves the transformation of a squamous layer of pregranulosa cells to a cuboidal phenotype (Eppig, 1991). It is often very difficult to distinguish the squamous and cuboidal cells morphologically in mice and, therefore, to 
determine whether granulosa cell division has started. A study in sheep (Lundy et al., 1999) showed that proliferating cell nuclear antigen, a marker for DNA replication, is detectable in flattened granulosa cells of type 1 follicles. Similarly, Hirshfield (1991) demonstrated that flattened granulosa cells of rat follicles incorporate $\left[{ }^{3} \mathrm{H}\right]$ thymidine, indicating that granulosa cell proliferation precedes differentiation.

The aim of the present study was to use morphological characteristics, coupled with the incorporation of a thymidine analogue, bromodeoxyuridine (BrdU), to identify follicles considered to be quiescent, and to ascertain whether these follicles could be correlated with a biochemical marker of apoptosis, namely active caspase-3. This study highlights some important attributes relating to the growth and atresia of small follicles in the mouse ovary.

\section{Materials and Methods}

\section{Animals}

Normal outbred C57BL/6 mice were purchased from the Department of Laboratory Animal Sciences, University of Otago, Dunedin. The mice were housed under standard (12 h light: $12 \mathrm{~h}$ dark) conditions and provided with commercial pelleted food and water ad libitum. Mice were killed by cervical dislocation and ovaries designated for morphometric analyses were collected from mice at 1 week $(n=5)$ and 6 weeks of age $(n=6)$. Caspase-3 expression and BrdU incorporation were examined in ovaries removed from separate groups of mice at 6 weeks of age $(n=6$ and 7 , respectively). The experimental use of these animals was approved by the University of Otago Animal Ethics Committee AEC No 73/99, 35/01.

\section{Morphological identification of small ovarian follicles}

Whole ovaries were fixed in Bouin's fluid, dehydrated and polymerized in glycolmethacrylate resin. Blocks were positioned isotropically using the 'orientator' (Mattfeldt et al., 1990). Serial sections, $30 \mu \mathrm{m}$ in thickness, were generated using systematic random sampling strategies and then stained with periodic acid-Schiff. Follicles classified as small according to Pedersen and Peters (1968), and the absence of a discernible zona pellucida and/or thecal layer, were selected randomly under a $\times 100$ oil immersion objective and viewed under an Olympus AX70 microscope. Follicle and oocyte diameters were recorded when the section was focused through the oocyte nucleolus (SON) and measurements were obtained for an unbiased estimate of the number of granulosa cells using the 'nucleator' technique originally described by Bagger et al. (1993) and applied in sheep ovary by Lundy et al. (1999). In brief, the SON of a randomly selected follicle was brought into focus and the image captured on a computer monitor. As the image was focused through the section (at a predefined depth), only granulosa cell nuclei that came into focus but were not in focus at the bottom of the section were counted.
The real distances between each of these sampled nuclei and the oocyte nucleolus were measured with the $\mathrm{NIH}$ microscale software and entered into the following equation: $\quad N_{\text {nu }}=1 / f_{2} \cdot 2 . \Sigma d / h$, where $1 / f_{2}$ represents the fraction of the dissector in the field of view; 2 is a constant for isotropically orientated sections; and $\Sigma d / h$ is the sum of the distances recorded for each sampled follicle divided by the depth of sampling ( $z$ axis).

The BrdU-treated mice received an i.p. injection $(0.2 \mathrm{ml})$

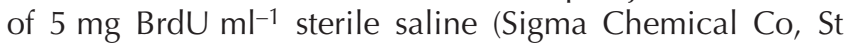
Louis, MO) three times in a $12 \mathrm{~h}$ period to correlate these attributes with growth or granulosa cell inactivity. A control mouse received sterile saline only. Small BrdU-positive follicles were localized using immunohistochemistry, and measurements through the SON were recorded.

\section{Immunohistochemistry}

All ovaries retrieved for immunohistochemistry were fixed in freshly prepared $4 \%(\mathrm{w} / \mathrm{v})$ paraformaldehyde in $0.1 \mathrm{~mol} \mathrm{PBS}^{-1}$ and processed overnight in paraffin wax. A systematic random sampling strategy (across all tissue) was used to yield $>130$ and 100 sections of $4 \mu \mathrm{m}$ for BrdU and caspase- 3 analysis, respectively. In brief, the paraffin wax was removed and the sections rehydrated and exposed to antigen unmasking in 0.1 mol Tris- $\mathrm{HCl}$ buffer $\mathrm{l}^{-1}(\mathrm{pH} 10)$ with $5 \%(\mathrm{w} / \mathrm{v})$ urea by heating for $20 \mathrm{~min}$ in a Sharp 1000 watt microwave oven for caspase- 3 or $0.1 \mathrm{mg}$ proteinase $\mathrm{K} \mathrm{ml}^{-1}$ (Sigma) in 0.1 mol Tris-EDTA buffer ${ }^{-1}$ ( $\mathrm{pH} 7.4$ ) followed by $4 \mathrm{~mol} \mathrm{HCl} \mathrm{I}^{-1}$ for BrdU. Peroxidase activity was quenched with $0.3 \%(\mathrm{v} / \mathrm{v}) \mathrm{H}_{2} \mathrm{O}_{2}$. Sections were blocked with a 1:200 dilution of donkey serum and incubated at $37^{\circ} \mathrm{C}$ for $1 \mathrm{~h}$ with $2 \mu \mathrm{g}$ rabbit anti-active caspase- 3 monoclonal antibody $\mathrm{ml}^{-1}$ (Research Diagnostics Inc, Flanders, NJ) followed by biotinylated anti-rabbit IgG (Amersham Pharmacia Biotech, Bucks) for caspase-3 immunostaining. Sections were incubated with 1:50 anti-BrdU (Dako, Carpinteria, CA) followed by biotinylated anti-mouse IgG (Amersham) for BrdU detection. Signals were amplified with streptavidin-biotinylated horseradish peroxidase complex (Amersham), developed with 3-amino9-ethylcarbazole (Sigma), counterstained with haematoxylin and analysed under a light microscope. In the control sections, the primary antibody was replaced with an equivalent amount of primary antibody dilution buffer or Ig isotype serum.

\section{Western immunoblot analysis}

Pairs of whole mouse ovaries were homogenized at $4^{\circ} \mathrm{C}$ in lysis buffer consisting of 50 mmol Tris- $-\mathrm{HCl} \mathrm{I}^{-1}(\mathrm{pH} 7.5)$, $5 \%(\mathrm{w} / \mathrm{v})$ sodium dodecyl sulphate, $5 \%(\mathrm{v} / \mathrm{v})$ glycerol, $6 \mathrm{~mol}$ urea $\mathrm{I}^{-1}$ and $10 \mu \mathrm{l}$ protease inhibitor cocktail (Sigma). Homogenates were centrifuged at $13000 \mathrm{~g}$ for $30 \mathrm{~min}$ and the supernatants collected. Total protein was estimated with the Pierce BCA protein assay (Rockford, IL). Thirty micrograms of protein was loaded on to a $10 \%(\mathrm{w} / \mathrm{v})$ SDS-polyacrylamide gel and separated under reducing 
Table 1. Characteristics of small follicles in the mouse ovary

\begin{tabular}{|c|c|c|c|c|c|c|}
\hline & $\begin{array}{l}\text { Total number of } \\
\text { small follicles } \\
\text { studied }\end{array}$ & GCSON & Nucleator & $\begin{array}{l}\text { Diameter of } \\
\text { oocyte }(\mu \mathrm{m})\end{array}$ & $\begin{array}{l}\text { Diameter of } \\
\text { follicle }(\mu \mathrm{m})\end{array}$ & $\begin{array}{l}\text { Number of } \\
\text { granulosa } \\
\text { cell layers }\end{array}$ \\
\hline $\begin{array}{l}\text { Postnatal } \\
\text { (1 week) }\end{array}$ & 59 & $\begin{array}{c}4.1 \\
(0,12)\end{array}$ & $\begin{array}{c}26.6 \\
(0,106.3)\end{array}$ & $\begin{array}{c}23.5 \\
(16.4,39.4)^{\mathrm{a}}\end{array}$ & $\begin{array}{c}31.7 \\
(18.5,52.7)^{\mathrm{a}}\end{array}$ & 1 \\
\hline $\begin{array}{l}\text { Peripubertal } \\
\text { ( } 6 \text { weeks) }\end{array}$ & 70 & $\begin{array}{c}4.0 \\
(0,18)\end{array}$ & $\begin{array}{c}22.1 \\
(2.5,136.5)\end{array}$ & $\begin{array}{c}17.5 \\
(9.7,36.2)^{b}\end{array}$ & $\begin{array}{c}25.6 \\
(14.8,57.6)^{b}\end{array}$ & 1 \\
\hline BrdU-positive & $18 / 178$ & $\mathrm{~N} / \mathrm{A}$ & $\mathrm{N} / \mathrm{A}$ & $>14.5$ & $>23.3$ & $\geqslant 1$ \\
\hline Active caspase-3-positive & $0 / 161$ & N/A & $\mathrm{N} / \mathrm{A}$ & Not measured & Not measured & $\geqslant 2$ \\
\hline
\end{tabular}

GCSON: values for the number of granulosa cells in the section through the oocyte nucleolus; nucleator: the total number of granulosa cells per follicle determined by the nucleator; BrdU: bromodeoxyuridine; N/A: not applicable.

The GCSON, nucleator, oocyte and follicle diameters are presented as geometric means and ranges (in parentheses).

${ }^{a b}$ Values within the same column with different superscripts are significantly different $(P<0.001)$.

conditions using a BioRad MiniProtean II unit. Proteins were electrotransferred with a BioRad Mini TransBlot cell on to a nitrocellulose membrane, blocked with $3 \%(\mathrm{w} / \mathrm{v})$ non-fat milk powder and $0.05 \%(\mathrm{v} / \mathrm{v})$ Tween 20, and probed with 1:100 anti-caspase-3 polyclonal antibody (Santa Cruz Biotech, Santa Cruz, CA) for $3 \mathrm{~h}$ at room temperature. Membranes were incubated with an anti-goat horseradish peroxidase conjugated secondary antibody (Sigma) and developed with ECL chemiluminescence according to the manufacturer's instructions (Amersham). This procedure was repeated three times to confirm consistency within and between samples.

\section{Statistical analysis}

The data for follicle characteristics were represented as geometric means and ranges. All follicles within a treatment group were pooled for statistical purposes and therefore animal-to-animal variation was not considered. Relationships between the number of granulosa cells and oocyte or follicle diameters were analysed by regression analyses.

\section{Results}

\section{Follicle characteristics}

Small follicles were characterized by morphological measurements (Table 1). The number of constituent granulosa cells per follicle was consistent between the two age groups as confirmed by both the 'nucleator' and the number of granulosa cells in the section through the oocyte nucleolus. The number of granulosa cells recorded in the SON of small follicles was $\leqslant 18$ in the postnatal and peripubertal age groups, which is consistent with the classification of small follicles reported by Pedersen and Peters (1968).

The size of follicles (diameter of oocytes and follicles) was significantly smaller in the peripubertal age group compared with the postnatal age group $(P<0.001)$. There

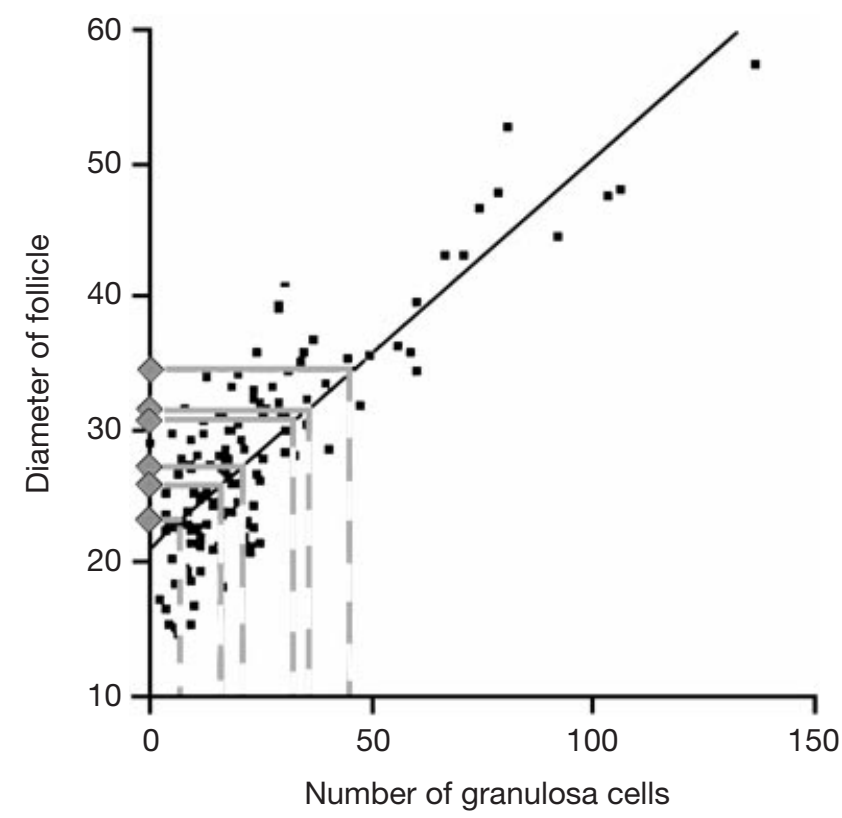

Fig. 1. Relationship between the diameter of small, single-layered follicles and the number of granulosa cells per follicle as determined by the 'nucleator' in mice. The diameters of bromodeoxyuridine (BrdU)-positive follicles (sectioned through the oocyte nucleolus) are represented along the $y$ axis by diamond symbols.

was a positive correlation between the number of granulosa cells and the size of the follicle (Fig. 1), which was independent of age $(P<0.001)$. The diameter of the oocytes of all follicles measured showed a positive correlation with the diameter of their constituent follicles $\left(r^{2}=0.91\right)$.

\section{BrdU incorporation}

In all animals studied, BrdU was incorporated into the nuclei of both granulosa and thecal cells of growing follicles, including a proportion (18 of $178 ; 10 \%$; Table 1 ) of 

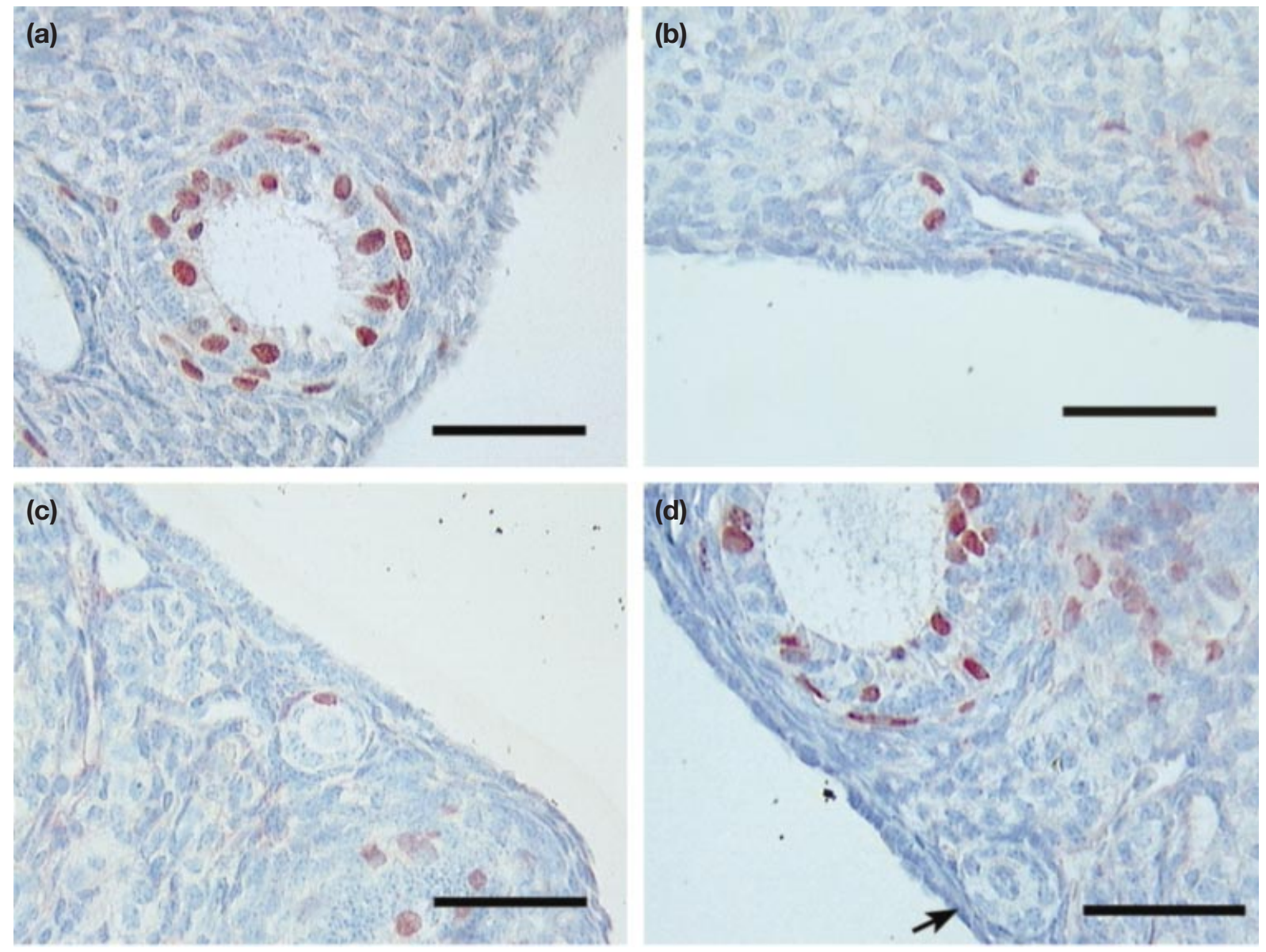

Fig. 2. Immunostaining of granulosa cells in the mouse ovary showing incorporation of bromodeoxyuridine (BrdU) in (a,d) large preantral and $(b, c)$ small, single-layered mouse follicles. The arrow indicates a BrdU-negative follicle. Scale bars represent $50 \mu \mathrm{m}$.

those classified as small (Fig. 2). Measurements of BrdUpositive small follicles taken throughout a range of sizes show that (Fig. 1) BrdU incorporation was detected in follicles of any size and containing any number of granulosa cells.

\section{Expression of caspase 3}

The inactive pro-form of caspase- 3 was detected as a $32 \mathrm{kDa}$ band in western blots of tissue extracts of mouse ovary (Fig. 3). The active form was localized in the granulosa cells of larger preantral and small antral follicles; staining was also evident in some oocytes of small preantral follicles (Fig. 4) and luteal cells of regressing corpora lutea (Fig. 4). Staining was never observed in thecal cells, including those that surrounded atretic follicles. Active caspase-3 was detected in follicles that were not considered to be morphologically atretic (that is, follicles in which no pyknotic or abnormal nuclei were observed). In some preantral follicles, an enlarged immunopositive oocyte was often associated with underdeveloped granulosa cell layers and an absence of surrounding thecal cells. Active caspase- 3 was never found in the granulosa cells of any small, single-layered follicles (Table 1) or large preovulatory follicles with healthy granulosa cells (Table 2). Immunostaining was not observed in the control sections, whether the primary antibody was replaced with dilution buffer or with Ig isotype serum.

\section{Discussion}

The main aim of the present study was to investigate the occurrence of atresia in non-growing follicles. It was necessary to discriminate quiescent follicles from follicles that had already started to develop by correlating morphological characteristics with granulosa cell proliferation. It was apparent that the number of granulosa cells was directly proportional to the size of the follicle, and that BrdU incorporation into granulosa cells of small follicles indicated evidence of granulosa cell proliferation. The fact that BrdU was incorporated into small follicles of any diameter indicates that BrdU incorporation occurs independently of both follicle size and number of granulosa 
Table 2. Immunostaining for active caspase- 3 in mouse ovarian follicles at different stages of growth

\begin{tabular}{lccc}
\hline & & Granulosa & Theca \\
Follicular stage & Oocyte & cells & interna cells \\
\hline Small (primordial and primary) & - & - & - \\
Small preantral & + & - & - \\
Large preantral & + & ++ & - \\
Small antral & - & ++ & - \\
Large antral & - & ++ & - \\
Preovulatory & - & - & \\
\hline
\end{tabular}

The results are based on the proportion of follicles with immunopositive cells.

$(-)$ : no immunostaining observed (within the oocyte, granulosa or theca interna cells) of a particular stage of follicular development; (+): occasional but infrequent immunostaining; and $(++)$ : relatively frequent immunostaining.

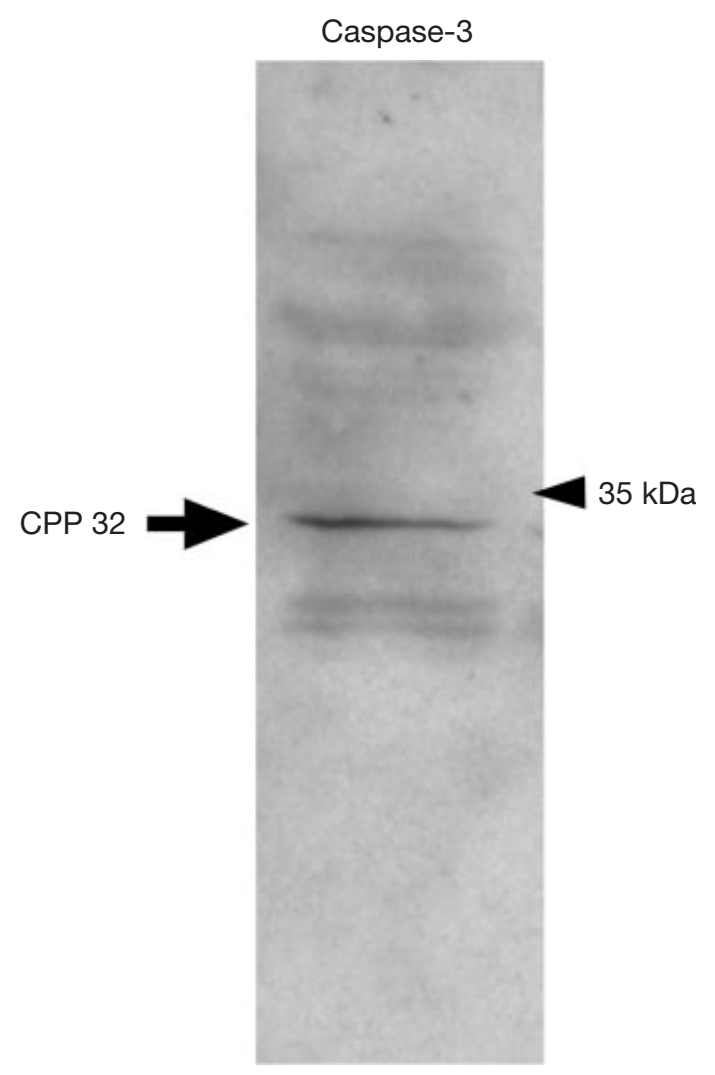

Fig. 3. Western blot analysis of the expression of caspase- 3 in mouse ovarian tissue extracts. The inactive form (CPP 32) was deleted at $32 \mathrm{kDa}$.

cells. Although small follicles are formed shortly after birth in mice (Hirshfield, 1991), the size and number of granulosa cells when the follicle is arrested may not have an effect on the order of follicle recruitment after birth.

Both the oocyte and follicle diameters were smaller in peripubertal mice compared with postnatal mice. This change in size was not proportional to the number of constituent granulosa cells indicating that there is a fixed number of cells in the small follicles, despite the fact that size may be influenced by larger adjacent structures, such as corpora lutea or developing follicles. Consequently, it is likely that the supply of small follicles in the mouse ovary exists as a resting pool rather than a cohort of slow-growing follicles, in which case these follicles would have been likely to show an increase in the number of granulosa cells per follicle as the ovary matured. Although most (> 89\%) of the small follicles that did not incorporate BrdU could be construed as resting, it is equally likely that BrdU-positive cells were simply not selected in the $5 \mu \mathrm{m}$ plane of section. Furthermore, it is also possible that not every dividing granulosa cell passed through the $\mathrm{S}$-phase of the cell cycle during the $12 \mathrm{~h}$ period examined. A previous study on follicle cell proliferation in the rat ovary using $\left[{ }^{3} \mathrm{H}\right]$ thymidine infusion (Hirshfield, 1989) indicated that the duration of the cell cycle in granulosa cells may exceed 7 days. In the same study, it was also noted that a proportion of very small follicles (with $\leqslant 4$ granulosa cells in a cross-section) had at least one labelled cell. This finding further supports the contention that the smallest follicles in the rodent ovary have the potential to develop irrespective of size or number of cells.

Under normal physiological conditions, morphological signs of atresia, such as nuclear pyknosis in large follicles, can easily be identified by the relatively large number of constituent granulosa cells and the propensity that these follicles have to be eliminated. Conversely, atresia of small follicles is more difficult to assess given their smaller size and considerably smaller number of constituent cells and, therefore, the requirement for an accurate marker of follicle cell apoptosis other than morphological criteria is essential and remains to be determined in small follicles. The active form of caspase-3 has been used as a marker for cell death in a number of tissues, particularly in tissues that show signs of degeneration as a consequence of disease or ageing (Hartmann et al., 2000). Although localization of active caspase-3 was found to be a useful indicator of follicular atresia in larger follicles of the mouse ovary, active caspase-3 was never observed in granulosa cells of small follicles. These results are consistent with those of Matikainen et al. (2001) who also did not detect the processed form of caspase-3 in small follicles of the human ovary. Little is known about the half-life of biologically active caspase- 3 in the ovary; however, given the number of small follicles observed, it is unlikely that the period of caspase-3 activation in either the oocyte or granulosa cells of small follicles was too short to be detected at any point. Lee et al. (2000) showed that primordial follicle degeneration that is induced by high doses of $\gamma$-irradiation proceeds at a much faster rate than that of larger follicles, and thus the time course of atresia of small quiescent follicles may be too rapid to be detected by current methods.

Morphologically 'atretic' primordial follicles have been described (Kondo et al., 1996; Perez et al., 1999; Lee et al., 2000). However, studies investigating the demise of primordial follicles using in situ TdT-mediated dUTP nick- 

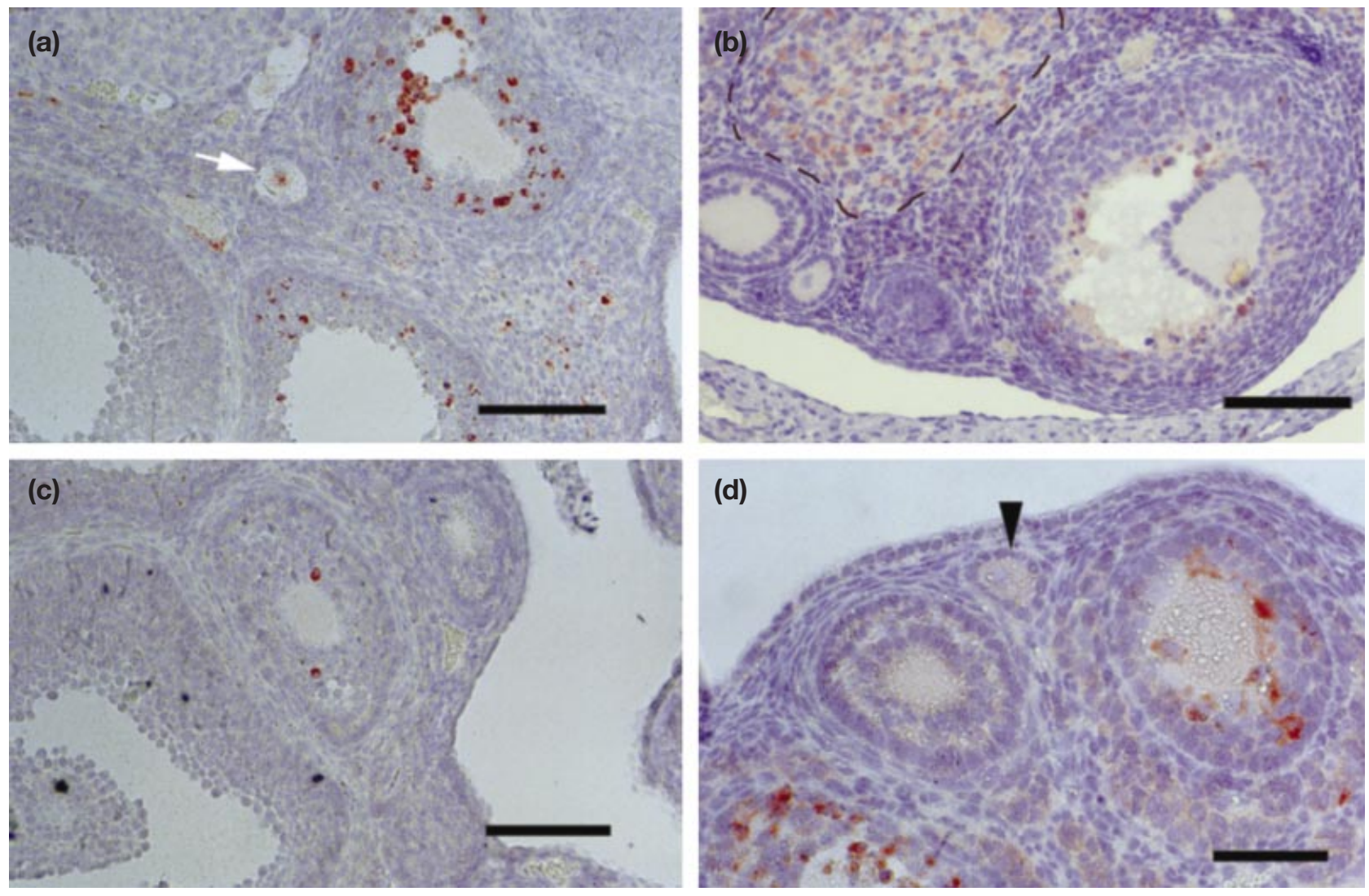

Fig. 4. Immunostaining of active caspase-3 in the mouse ovary. (a,b,d) Follicles with many immunopositive cells were considered to be at the late stages of atresia, whereas (c) follicles with few positive cells may indicate early atresia. (a) The arrow shows an immunopositive oocyte; (b) the hatched line shows a regressing corpus luteum and (d) the arrowhead shows a small, single-layered immunonegative follicle. Scale bar represents (a,b,c) $100 \mu \mathrm{m}$ and (d) $50 \mu \mathrm{m}$.

end labelling (TUNEL) or the localization of other apoptotic components have not been well documented in the normal ovary. Devine et al. (2000) discovered that, in the rat ovary, atresia of primordial follicles, as determined by ultrastructural observations, involved the loss of the oocyte, which was atypical of apoptosis and, thus, proposed that the mechanism of oocyte death may operate in a different manner to that of granulosa cell apoptosis. Similarly, Bergeron et al. (1998) described the functional requirement of caspase-2 for oocyte apoptosis, and this was supported by the findings of Matikainen et al. (2001), who determined that oocyte death was unaffected in caspase-3 gene knockout mice. In the present study, active caspase-3 was localized in several oocytes of preantral follicles, indicating that the integrity of this pathway may still be preserved and activated under certain conditions, although the details of these conditions remain to be elucidated.

Processed caspase-3 may also be found in luteal cells of degenerating corpora lutea. It is well established that luteolysis occurs via apoptosis of luteal cells (Zeleznik et al., 1989), which is in agreement with the evidence that cells of this origin are activating capase- 3 during apoptosis, and that this pathway of execution is conserved subsequent to differentiation. Furthermore, in all atretic follicles observed, active caspase- 3 was never detected in cells of thecal origin, which have been shown to undergo apoptosis during follicular atresia in other species, including sheep (O'Shea et al., 1978), rats (Foghi et al., 1997) and humans (Matikainen et al., 2001), implying that apoptosis of cells of thecal origin is limited or may occur via a different mechanism in mice.

In summary, the results of the present study indicate that, in the mouse ovary, the pool of primordial follicles considered to be in a quiescent state are difficult to identify by morphology alone. Although BrdU may be incorporated into granulosa cells of follicles from a range of sizes, it is possible that these cells are spontaneously cycling independent of follicular growth and, therefore, maintaining a constant number of healthy support cells for the oocyte. However, this process is unlikely given that caspase-3 activity was not observed in these cells in any of the sections studied. Therefore, this finding indicates that the mechanism by which small follicles undergo atresia is independent of caspase-3 activation, or that these follicles express an increased resistance to the physiological factors that normally induce apoptosis. 
The authors would like to thank S. J. Bunn for advice with western blotting and P. Garry for technical assistance. This work was supported by a New Zealand Lottery Health Grant.

\section{References}

Bagger PV, Bang L, Christiansen MD, Gundersen HJ and Mortensen L (1993) Total number of particles in a bounded region estimated directly with the nucleator: granulosa cell number in ovarian follicles American Journal of Obstetrics and Gynecology 168 724-731

Baker TG (1963) A quantitative and cytological study of germ cells in human ovaries Proceedings of the Royal Society B 158 417-433

Bergeron L, Perez GI, Macdonald G et al., (1998) Defects in regulation of apoptosis in caspase-2-deficient mice Genes and Development 12 1304-1314

Boone DL and Tsang BK (1998) Caspase-3 in the rat ovary: localization and possible role in follicular atresia and luteal regression Biology of Reproduction 58 1533-1539

Cohen GM (1997) Caspases: the executioners of apoptosis Biochemical Journal 326 1-16

Devine PJ, Payne CM, McCuskey MK and Hoyer PB (2000) Ultrastructural evaluation of oocytes during atresia in rat ovarian follicles Biology of Reproduction 63 1245-1252

Earnshaw WC, Martins LM and Kaufmann SH (1999) Mammalian caspases: structure, activation, substrates and functions during apoptosis Annual Review of Biochemistry 68 383-424

Eppig JJ (1991) Intercommunication between mammalian oocytes and companion somatic cells Bioessays 13 569-574

Findlay JK and Drummond AE (1999) Regulation of the FSH receptor in the ovary Trends in Endocrinology and Metabolism 10 183-188

Foghi A, Teerds KJ, van der Donk H and Dorrington J (1997) Induction of apoptosis in rat thecal/interstitial cells by transforming growth factor alpha plus transforming growth factor beta in vitro. Journal of Endocrinology 153 169-178

Gougeon A (1996) Regulation of ovarian follicular development in primates: facts and hypotheses Endocrine Reviews 17 121-155

Hakuno N, Koji T, Yano T, Kobayashi N, Tsutsumi O, Taketani $Y$ and Nakane PK (1996) Fas/APO-1/CD95 system as a mediator of granulosa cell apoptosis in ovarian follicle atresia Endocrinology 137 1938-1948

Hartmann A, Hunot S, Michel PP et al., (2000) Caspase-3: a vulnerability factor and final effector in apoptotic death of dopaminergic neurons in Parkinson's disease Proceedings National Academy of Sciences USA 97 2875-2880

Hirshfield AN (1989) Granulosa cell proliferation in very small follicles of cycling rats studied by long-term continuous tritiated-thymidine infusion Biology of Reproduction 41 309-316

Hirshfield AN (1991) Development of follicles in the mammalian ovary International Review of Cytology 124 43-101

Johnson AL and Bridgham JT (2000) Caspase-3 and -6 expression and enzyme activity in hen granulosa cells Biology of Reproduction 62 589-598

Kaipia A and Hsueh AJ (1997) Regulation of ovarian follicle atresia Annual Review of Physiology 59 349-363
Kondo H, Maruo T, Peng X and Mochizuki M (1996) Immunological evidence for the expression of the Fas antigen in the infant and adult human ovary during follicular regression and atresia Journal of Clinical Endocrinology and Metabolism 81 2702-2710

Lee CJ, Park HH, Do BR, Yoon Y and Kim JK (2000) Natural and radiationinduced degeneration of primordial and primary follicles in mouse ovary Animal Reproduction Science 59 109-117

Lundy T, Smith P, O'Connell A, Hudson NL and McNatty KP (1999) Populations of granulosa cells in small follicles of the sheep ovary Journal of Reproduction and Fertility 115 251-262

Matikainen T, Perez GI, Zheng TS, Kluzak TR, Rueda BR, Flavell RA and Tilly JL (2001) Caspase-3 gene knockout defines cell lineage specificity for programmed cell death signaling in the ovary Endocrinology 142 2468-2480

Mattfeldt T, Mall G, Gharehbaghi H and Moller P (1990) Estimation of surface area and length with the orientator Journal of Microscopy 159 $301-317$

Morita Y and Tilly JL (1999) Oocyte apoptosis: like sand through an hourglass Developmental Biology 213 1-17

O'Shea JD, Hay MF and Cran DG (1978) Ultrastructural changes in the theca interna during follicular atresia in sheep Journal of Reproduction and Fertility 54 183-187

Pedersen T and Peters H (1968) Proposal for a classification of oocytes and follicles in the mouse ovary Journal of Reproduction and Fertility $\mathbf{1 7}$ 555-557

Perez GI, Robles R, Knudson CM, Flaws JA, Korsmeyer SJ and Tilly JL (1999) Prolongation of ovarian lifespan into advanced chronological age by Bax-deficiency Nature Genetics 21 200-203

Sakamaki K, Yoshida H, Nishimura $\mathrm{Y}$, Nishikawa S, Manabe $\mathrm{N}$ and Yonehara S (1997) Involvement of Fas antigen in ovarian follicular atresia and luteolysis Molecular Reproduction and Development $\mathbf{4 7}$ $11-18$

Tilly JL (1996) Apoptosis and ovarian function Reviews of Reproduction 1 $162-172$

Tilly JL, Tilly KI, Kenton ML and Johnson AL (1995) Expression of members of the bcl-2 gene family in the immature rat ovary: equine chorionic gonadotropin-mediated inhibition of granulosa cell apoptosis is associated with decreased bax and constitutive bcl-2 and bcl-xlong messenger ribonucleic acid levels Endocrinology 136 232-241

Van Nassauw L, Tao L and Harrisson F (1999) Distribution of apoptosisrelated proteins in the quail ovary during folliculogenesis: BCL-2, BAX and CPP32 Acta Histochemica 101 103-112

Zeleznik AJ, Ihrig LL and Bassett SG (1989) Developmental expression of $\mathrm{Ca}^{++} / \mathrm{Mg}^{++}$-dependent endonuclease activity in rat granulosa and luteal cells Endocrinology 125 2218-2220

Received 7 February 2002.

First decision 8 April 2002.

Revised manuscript received 7 July 2002.

Accepted 16 July 2002. 